\title{
DÜBLIN
}

Technological University Dublin

ARROW@TU Dublin

2013-6

\section{The Effect of Truck Permitting Policy on US Bridge Loading}

\author{
Eugene J. OBrien \\ University College Dublin, eugene.obrien@ucd.ie \\ Bernard Enright \\ Technological University Dublin, bernard.enright@tudublin.ie \\ Cathal Leahy \\ University College Dublin
}

Follow this and additional works at: https://arrow.tudublin.ie/engschcivcon

Part of the Civil Engineering Commons, and the Structural Engineering Commons

\section{Recommended Citation}

OBrien, E.J., Enright, B., Leahy, C. (2013), 'The effect of truck permitting policy on US bridge loading' 11th International Conference on Structural Safety \& Reliability (ICOSSAR), New York.

This Conference Paper is brought to you for free and open access by the School of Civil and Structural Engineering at ARROW@TU Dublin. It has been accepted for inclusion in Conference papers by an authorized administrator of ARROW@TU Dublin. For more information, please contact arrow.admin@tudublin.ie, aisling.coyne@tudublin.ie,gerard.connolly@tudublin.ie.

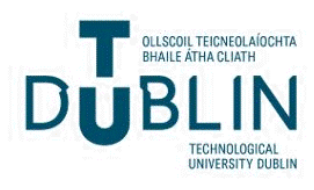




\title{
The effect of truck permitting policy on US bridge loading
}

\author{
E.J. OBrien \\ University College Dublin, Newstead, Dublin 4, Ireland \\ B. Enright \\ Dublin Institute of Technology, Bolton Street, Dublin 1, Ireland \\ C. Leahy \\ University College Dublin, Newstead, Dublin 4, Ireland
}

\begin{abstract}
Accurate estimates of characteristic traffic load effects are greatly beneficial in prioritizing bridges for repair and replacement. The extreme loading events likely to cause characteristic load effects are dominated by very heavy permit trucks. As these trucks are significantly heavier and are subject to stricter controls than standard trucks, they may be treated separately from the general truck population. This paper examines truck loading at 3 Weigh-in-Motion (WIM) sites in the United States and develops filtering rules to identify permit trucks based on the available axle spacing information. Once all trucks have been classified, permit and standard trucks are examined separately to get a better understanding of their importance for bridge loading. A Monte Carlo simulation model is developed which allows permit trucks to be simulated independently of the standard truck population. The truck simulation model is used to investigate the changes in characteristic load effects resulting from changes in permit-issuing policy.
\end{abstract}

\section{INTRODUCTION}

New bridges are designed to carry notional traffic loading, deemed to represent the worst extremes of loading that can be reasonably expected in the bridge lifetime. Such models are conservative which is appropriate, given the modest marginal cost of providing additional load-carrying capacity. However, the situation is different when an existing bridge is being assessed. In such cases, excessive conservatism in the safety assessment will result in premature replacement and an unnecessary shortening of the bridge life. This paper focuses on the traffic loading part of the bridge safety assessment process. It describes a procedure to more accurately calculate characteristic load effects due to traffic.

Many authors have contributed to the bridge traffic loading literature since Weigh-in-Motion (WIM) data become widely available in the late 1990's (Jacob \& OBrien 2005). Until recently, characteristic maximum load effects (moment, shear force, etc.) were found by statistical extrapolation based on WIM measurements taken over relatively short periods of time (Nowak 1993, Flint \& Jacob 1996, Grave et al. 2005, Moses 2001, Sivakumar \& Ibrahim 2007). In general, this extrapolation has been done by fitting a statistical distribution to either the load effects calculated from the measured data, or to the results from Monte Carlo simulation, and then using the fitted distribution as the basis for extrapolation (Caprani \& OBrien 2006). The choice of a suitable statistical distribution can be problematic, and can lead to widely varying results.

In the development of U.S. and Canadian codes for bridge design, Nowak $(1993,1994)$ used measurements taken in Ontario in 1975 (Agarwal \& Wolkowicz 1975) for a total of 9250 trucks. Load effects are calculated for these trucks for different bridge spans and plotted on Normal probability paper. The curves are extrapolated to give estimates for the mean 75-year load effect, and the coefficient of variation is estimated by raising the distributions to a power based on typical truck volumes. This process requires a significant degree of engineering judgment and subjectivity, as noted by Miao and Chan (2002) and Gindy and Nassif (2006).

In the development of the Eurocode, traffic measurements were collected over some weeks at different times, and a number of different extrapolation techniques applied (O'Connor et al. 2001). Multimodal Normal and Gumbel distributions are fitted to measured load effects for individual loading events, and the Gumbel extreme value distribution is fitted to periodic maxima calculated from simulation. The Rice level-crossing formulation is also used (Flint \& Jacob 1996, O'Connor et al. 2001).

Bridge loading can be separated into that caused by standard vehicles ('normal' loading in Eurocode) and that caused by permit vehicles ('abnormal' load). In the US the AASHTO LRFD Bridge Design Specification (AASHTO 2010) separates trucks into normal vehicular use of the bridge, which includes 
normal trucks and routine permits, and special design vehicles, which are trucks above the limits for routine permits that require individual analysis. It can be argued that standard vehicles are not well controlled and should have a higher factor of safety or return period. Permit vehicles, on the other hand, are subject to a greater degree of control which may justify a lesser factor of safety or return period. Previous work has shown that characteristic load effects are caused predominantly by permit vehicles (Enright \& OBrien, 2012).

In this paper, WIM data from three states in the United States are filtered to separate apparent permit vehicles from standard vehicles. The two data subsets - apparent standard and apparent permit - are examined separately.

\section{WEIGH-IN-MOTION DATABASE}

For this study, data from three WIM sites in the United States is analyzed. This WIM data has been collected as part of a follow-on project of the Federal Highway Administration's Long Term Pavement Performance (LTPP) program for traffic data collection. In the early years of the LTPP, traffic data was collected with inconsistent quality control measures (Walker \& Cebon 2012). A plan was developed in 1999 under which, among other things, quality control was improved and implemented centrally. This led to a significant improvement in WIM data reliability. Since 2003, 'research quality' WIM data is being collected at 28 of the Specific Pavement Studies LTPP sites. Research Quality is, for this purpose, defined as 210 days of data per year of known calibration, meeting LTPP's accuracy requirements for steering and tandem axles, gross vehicle weight, vehicle length, speed, and axle spacing. The recommended WIM technologies include bending plate, load cell, and quartz sensors. The three sites used here all belong to this group of research-quality WIM sites.

Table 1 shows the details of the WIM sites used in this work. At all sites, only one lane in one direction is measured, that being the slow lane. All data was collected between $1^{\text {st }}$ January 2008 and $31^{\text {st }}$ December 2011.

Table 1. Details of WIM sites

\begin{tabular}{|l|l|l|l|}
\hline Site & Road & $\begin{array}{l}\text { Weekdays } \\
\text { of Data }\end{array}$ & $\begin{array}{l}\text { Average } \\
\text { Trucks/day }\end{array}$ \\
\hline Arizona & I-10 East & 996 & 4988 \\
\hline Illinois & I-57 North & 1008 & 3139 \\
\hline Indiana & US-93 North & 870 & 1489 \\
\hline
\end{tabular}

All raw WIM databases contain a certain amount of erroneous data. Before WIM data is analyzed this data must first be removed. In this study a set of rules is developed, based on the rules proposed by Enright (2010), to remove these errors.

\section{FILTERING PERMIT TRUCKS}

It is standard practice in the United States and Europe to analyze bridges separately for the effects of standard and permit vehicles. It is assumed that there is greater control on vehicles that require permits which justifies the use of a lesser factor of safety or return period. Separating standard and permit trucks is difficult in WIM data. While transponders or other devices may be used in the future to transmit data on the permit status of a vehicle to the roadside, this is not, to the authors' knowledge, a part of any current Weigh-in-Motion (WIM) system in the world today.

Arbitrarily identifying all vehicles outside the legal weight limit as having a permit would be problematic. In most WIM databases, there are significant numbers of standard vehicles with weights in excess of the legal limits. If these were excluded, it would put an upper limit on the weights of standard trucks and would render any statistical extrapolation of that data meaningless. In effect, characteristic load effects would converge to a limit as the return period approached infinity. While the load effects due to standard trucks tend to converge to a limit, it is not the limit corresponding to the legal maximum weight.

A set of filtering rules is therefore developed based on the numbers of axles and axle spacing. The resulting filtered data is separated into apparent standard and apparent permit vehicles. The apparent standard dataset may contain vehicles with silhouettes similar to standard trucks that have a permit. Similarly, the apparent permit dataset may contain vehicles that should have a permit but which do not. While this is not an ideal situation, it successfully separates the vehicles into sets that have distinctly different statistical properties.

Fig. 1 illustrates an example of filtered data from the I57 in Illinois, plotted on probability paper. The apparent standard vehicle data shows a clear noncritical trend and it can be seen that, if the trend is extrapolated, the characteristic maximum gross weight for 75-year or 1000-year return periods is much less than for the apparent permit set. Filtering in this way allows the two statistically dissimilar datasets to be separated and treated differently: the apparent standard is tending towards lower characteristic values but may justify a greater return period; the apparent permit tends towards higher characteristic values but these vehicles are better controlled and may justify little or no extrapolation. Caprani et al. (2008) have demonstrated the benefits of separating statistical data in this way. 


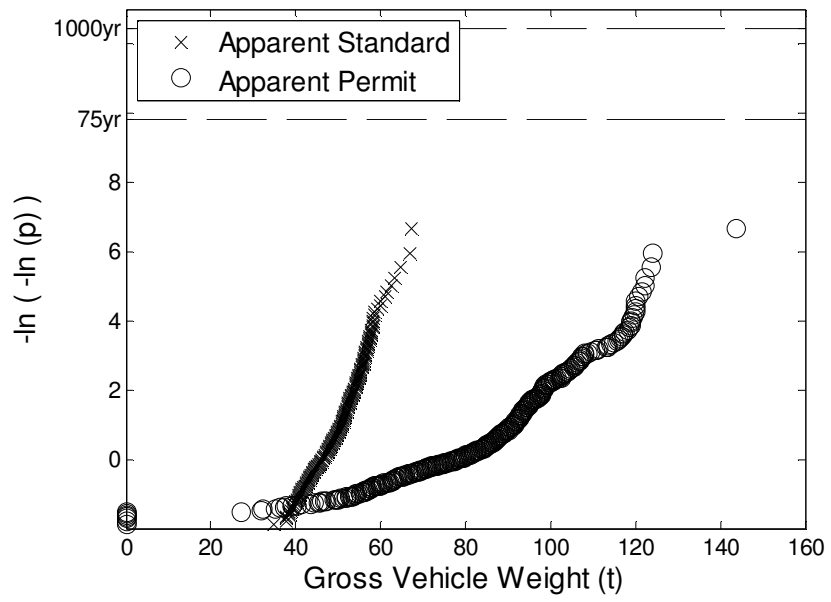

Figure 1. Gumbel probability paper plot of maximum daily gross vehicle weights for standard and permit trucks at the Illinois (IL) WIM site.

The rules adopted for filtering the data are as follows. A vehicle is assigned to the apparent permit set if it meets one or more of the following rules:

1. More than 9 axles.

2. Group of 4 (or more) axles at rear of truck.

3. More than 6 axles, with a tridem at rear (not a Long Combination Vehicle).

4. Articulated semi-trailer configuration which is longer than legal limit or has $>6$ axles.

5. Maximum inter-axle spacing less than $5.5 \mathrm{~m}$ and average spacing less than $2.7 \mathrm{~m}$ (mobile crane type).

\section{MONTE CARLO SIMULATION}

WIM data at the three sites is used to calibrate a Monte Carlo simulation model of traffic load on a number of bridges. This allows the implementation of 'long run' traffic load simulation (Enright \& OBrien 2012) whereby enough data is generated to reduce the element of uncertainty associated with the statistical extrapolation process. In this case, apparent standard vehicles are generated by continually re-sampling (bootstrapping) from the vehicle records available at each site. The focus of this study is the apparent permit vehicles and these are considered in more detail.

Three types of apparent permit vehicle are evident in the data: low loaders, mobile cranes and mobile cranes with dollies. Low loaders are characterized by one big axle spacing with more closely spaced axle groups on either side. The example of Fig. 2(a) is typical with a maximum axle spacing of $10.5 \mathrm{~m}$. Cranes are characterized by high average axle loads and small spacings. The example of Fig. 2(b) is found in both Europe and the United States. The example of Fig. 2(c) includes a trailing dolly to spread the load over a greater number of axles. This appears to be a product of the US Federal Bridge
Formula (Sivakumar et al. 2007) and is not generally found in Europe.

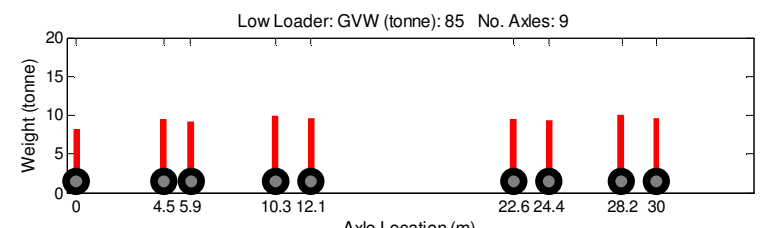

(a) Low loader

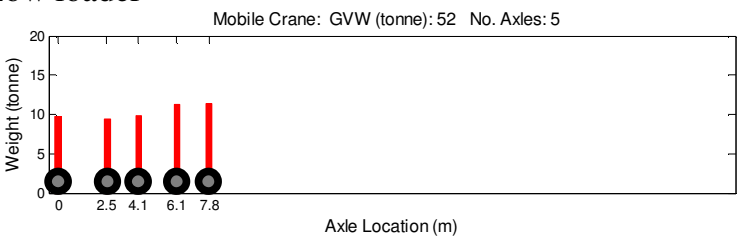

(b) Mobile crane

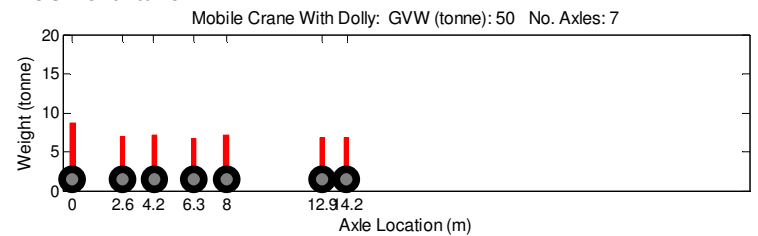

(c) Crane with trailing dolly

Figure 2. Apparent permit vehicle silhouettes found in the WIM data (traveling right to left)

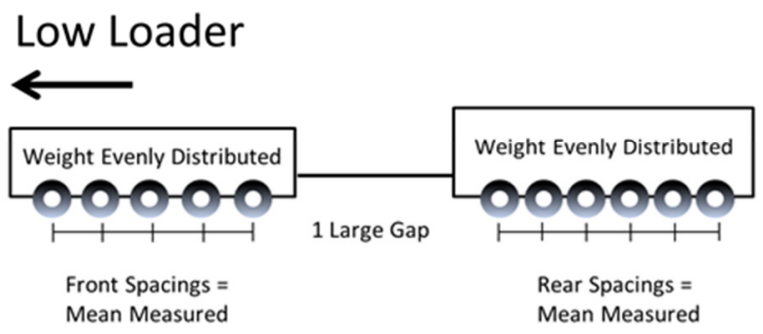

Mobile Crane

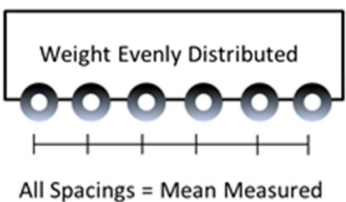

Mobile Crane With Dolly

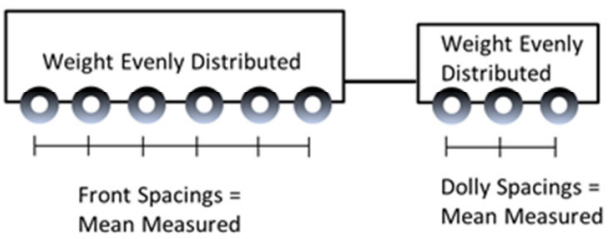

Figure 3. Summary of representative apparent permit vehicles

The measured vehicle records are found to fall into 3 general categories which have been standardized into 3 representative vehicles to simplify the simulation process. The representative vehicles, illustrated in Fig. 3, separate the axles on the vehicles 
into groups with equal axle weights and spacing with each group.

For each of the three apparent permit vehicle types, the tail of a bivariate Normal distribution is fitted to the tail of the measured gross weights and numbers of axles, as illustrated in Fig. 4. This bivariate fitting allows the simulation of weights beyond anything recorded and has the effect of randomizing the numbers of axles while retaining good consistency with the measurements. As only the extreme data is of interest, the bivariate distribution is fit to the 100 heaviest low loaders. For each of the crane type vehicles the distribution is fitted to the 50 heaviest, as there are less of these in the WIM data.

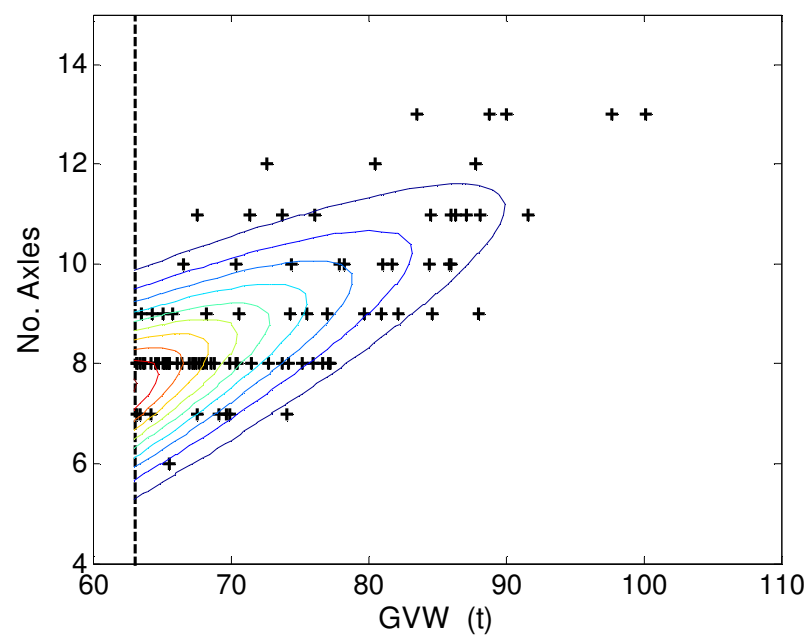

Figure 4. Contours of probability from a fit of the tail of a bivariate Normal distribution to gross vehicle weight (GVW) and numbers of axles for low loaders, at the Indiana WIM site.

Typical results are illustrated in the probability paper plot of Fig. 5. Maximum-per-day load effects, calculated directly from the 1008 days of measured data, are shown in red. These maximum-per-day values are for all apparent permits and standards. The standards, however, are unlikely to contribute as we have seen that permit trucks dominate the extreme loading events. The Monte Carlo simulation is run for a period representing 300 years. The simulated maximum-per-day data, shown in pink, can be seen to match the directly measured data quite well, confirming the insensitivity to the simplifications of Fig. 3. While the characteristic maximum 75-year load effect could have been taken directly, accuracy is improved by a best fitting of a Weibull distribution to the tail of the data (OBrien et al. 2010). In this case, least squares fitting is used to find the best fit to the top $2 \sqrt{ } n$ of the $n$ data points (Castillo 1988).

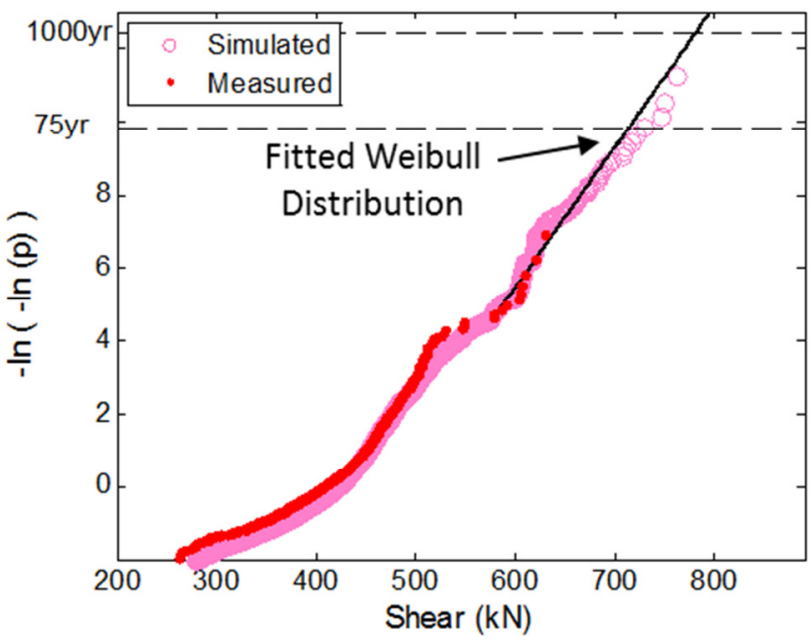

Figure 5. Interpolation on probability paper to find the characteristic maximum load effect for shear on $30 \mathrm{~m}$ bridge at the Illinois site.

For multi-lane bridges, single vehicle loading events have been shown to be dominant at the characteristic maximum level, when the transverse stiffness of the bridge is relatively low (Enright \& OBrien 2012). When the transverse stiffness is high, two vehicles commonly contribute to the characteristic maximum load effect. This latter is consistent with Turkstra's Rule (Getachew \& OBrien 2007) which predicts that the critical loading event will be caused by the characteristic maximum vehicle (in some sense) in one lane, combined with a typical vehicle in the other. The truck in the second lane is generally standard and its contribution to the characteristic load effect modest. For this work a high transverse stiffness is assumed for all cases.

The analysis is carried out for a range of bridge lengths and for three load effects: mid-span bending and end shear in simply supported bridges and central support moment in 2-span bridges. In each case, the characteristic 75-year load effect values are found. This process is repeated for each of the three WIM sites.

For all three sites, WIM data is only available in the slow lane of a multi-lane highway. Two-lane bridges are considered using the same slow-lane data in each lane. This is conservative: if the highway becomes a 2-lane bi-directional road, cars from the fast lane(s) will merge with the trucks in the slow lane and will tend to reduce the density of trucks, thereby reducing the probability of 2-truck meeting events on the bridge. It is also conservative for 2-lane same-direction bridges as data from two slow lanes is being used which has a much higher density of trucks than a fast lane alongside a slow lane. For the Arizona site where the truck flow is high, it is deemed unrealistic to have two lanes with this number of trucks and only single lane bridges are considered. 


\section{RESULTS}

Characteristic maximum load effects are found for a range of bridge lengths and influence lines. The entire process is repeated, assuming different weight restrictions on the apparent permit vehicles.

The legal weight limit in the United States is 36 tonnes (80 kips) but trucks can get routine permits up to a higher threshold beyond which they must be individually analyzed. This higher threshold for the most bridge-friendly configuration is determined at state level and is 113, 54 and 54 tonnes (250, 120 and 120 kips) for Arizona (AZ), Illinois (IL) and Indiana (IN) respectively (USDOT 2000). Weight restrictions can, in effect, only be applied to true permit vehicles. Such restrictions cannot be applied to those vehicles deemed by the filter to have permits but which do not. It has therefore been decided to impose simple percentage reductions in the maximum allowable weights of all apparent permit vehicles. This assumes the same amount of illegal overloading of apparent standards as currently exists at each site. The maximum allowable permit weight is restricted as a percentage of the mean maximum weekly (MMW) GVW. The MMW GVW is used as it allows sites with different levels of truck loading to be compared on the same graph. It is also a good measure of the aggressiveness of truck traffic for bridge loading (OBrien \& Enright 2012). The Arizona, Illinois and Indiana sites have a MMW GVW of 93, 99 and 65 tonnes respectively.

Some typical results are illustrated in Fig 6. There is random variation in the results due to the nature of the Monte Carlo simulation process. However, where the trend is consistent, it suggests that repeated simulations are likely to give similar results.

The extent of the 'savings' in load effect that are possible by reducing the maximum allowable weight of permit vehicles varies by load effect and span. It appears that the reduction in characteristic load effect increases with bridge span (Fig. 6(a) and 6(b)).

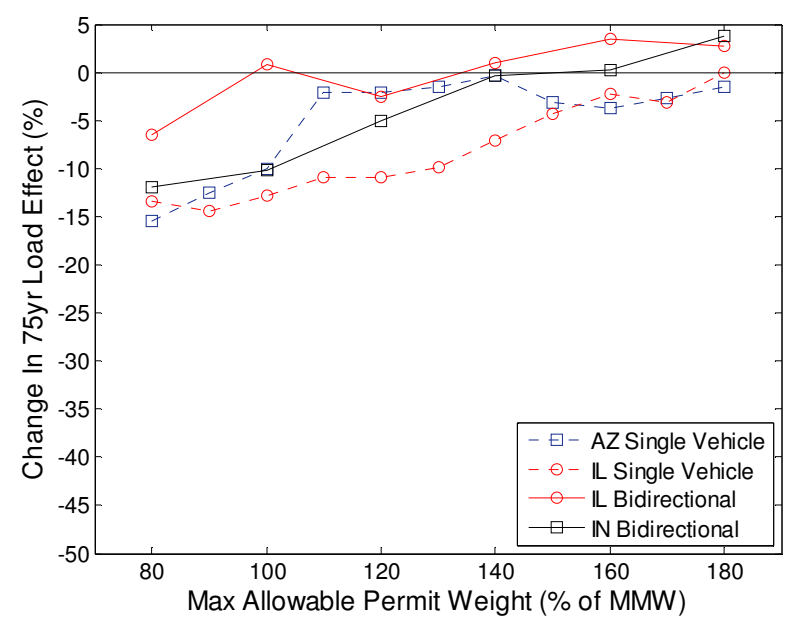

(a) Mid-span moment on simply supported $20 \mathrm{~m}$ span

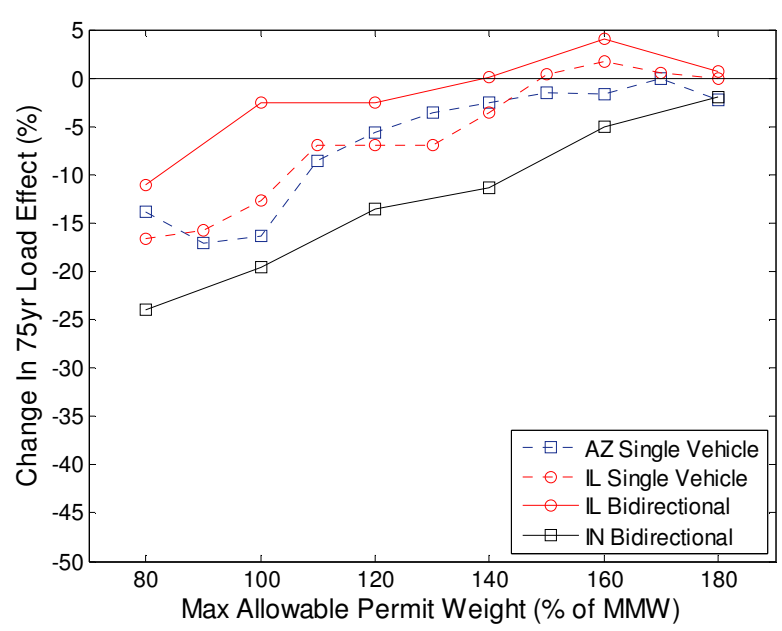

(b) Mid-span moment on simply supported $50 \mathrm{~m}$ span

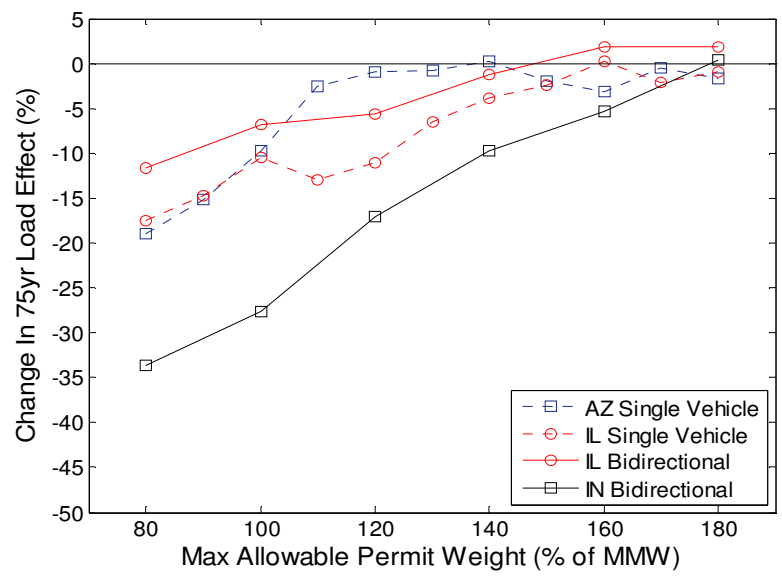

(c) End Shear on simply supported $30 \mathrm{~m}$ span

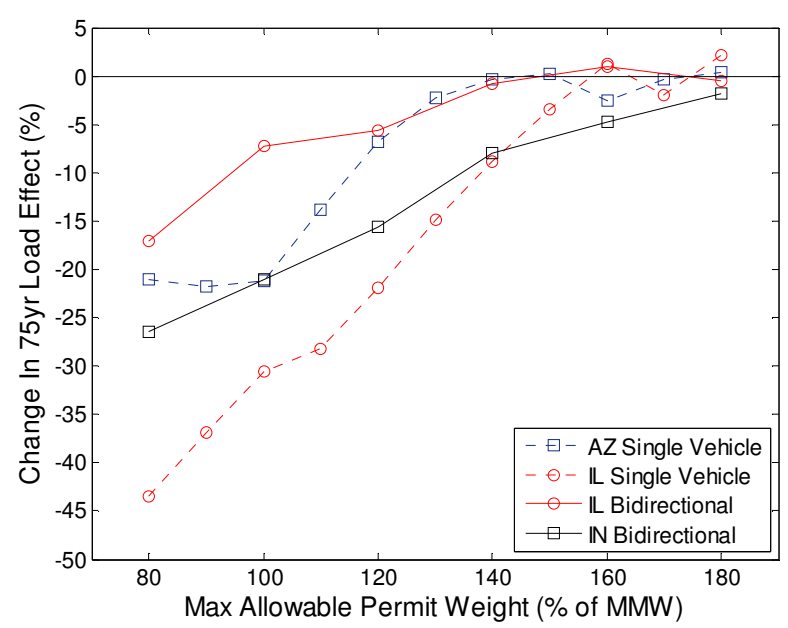

(d) Central support moment at centre of $50 \mathrm{~m}(2 \times 25 \mathrm{~m})$ bridge.

Figure 6. Effect of Restrictions on Maximum Weight of Apparent Permit Vehicles

In some cases an upper limit to the reductions can be seen (e.g., AZ, Single Vehicle in Fig. 6(d)) where the load effects caused by standard trucks become larger than those of the restricted permits. This limit is reached at all sites with further restrictions to permit trucks. The most significant point in these graphs is that by imposing restrictions on the weight of permit trucks, reductions in characteristic load effect of up to $45 \%$ can be achieved. 


\section{CONCLUSIONS}

This paper analyzes data from three American WIM sites. It uses a filter based on numbers of axles and axle spacing to separate vehicles that apparently have a permit from those that apparently do not. The approach greatly simplifies the analysis required to find the characteristic maximum load effects on bridges.

In the simulations, apparent standard (nonpermit) vehicles are simply bootstrapped from the database. Apparent permit vehicles are broken down into just three categories - low loaders, mobile cranes and cranes with dollies. These vehicle types are simplified (Fig. 3) and the simplified model calibrated against the WIM data. The resulting model is found to give good agreement when compared against the load effects calculated directly from the WIM data.

The implications of imposing upper limits on the weights of permit trucks is investigated. It is shown that the savings in characteristic 75-year maximum load effect vary by load effect and span and that savings of up to $45 \%$ are possible.

\section{ACKNOWLEDGEMENTS}

The authors gratefully acknowledge the Federal Highways Administration for access to an extensive database of WIM data and the Irish National Roads Authority for their financial support.

\section{REFERENCES}

AASHTO. 2010. AASHTO LRFD Bridge Design Specifications (5th ed.). Washington D.C.: American Association of State Highway and Transportation Officials.

Agarwal, A. C. and Wolkowicz, M. 1976. Interim report on Ontario Commercial Vehicle Survey 1975: Ministry of Transportation \& Communications, Ontario.

Caprani, C.C. \& OBrien, E.J., 2006. 'Statistical Computation for Extreme Bridge Traffic Load Effects', Proceedings of the Eighth International Conference on Computational Structures Technology, Eds. B.H.V. Topping, G. Montero and R. Montenegro, Las Palmas, Civil-Comp Press.

Caprani, C. C., OBrien, E. J. and McLachlan, G. 2008. 'Characteristic traffic load effects from a mixture of loading events on short to medium span bridges', Structural Safety, 30, 394-404.

Castillo, E., 1988. Extreme value theory in engineering, London: Academic Press.

Enright, B. 2010. Simulation of traffic loading on highway bridges. PhD Thesis. University College Dublin.

Enright, B., \& OBrien, E.J. 2012. Monte Carlo simulation of extreme traffic loading on short and medium span bridges. Structure and Infrastructure Engineering. doi: 10.1080/15732479.2012.688753.

Flint, A. R. and Jacob, B. 1996. Extreme Traffic Loads on Road Bridges and Target Values of Their Effects for Code
Calibration. Proceedings of IABSE Colloquium, Delft, The Netherlands: IABSE-AIPC-IVBH; 469-78.

Getachew, A. \& OBrien, E., 2007. Simplified site-specific traffic load models for bridge assessment. Structure and Infrastructure Engineering, 3(4), pp.303-311.

Gindy, M. and Nassif, H. H. 2006. Comparison of traffic load models based on simulation and measured data. Joint International Conference on Computing and Decision Making in Civil and Building Engineering, Montréal, Canada; [online] available from:

http://www.icccbexi.ca/html/en/AutIndex.htm\#G, accessed 8 May 2007

Grave, S., OBrien, E.J. and O'Connor, A.J. 2000. 'The Determination of Site-Specific Imposed Traffic Loadings on Existing Bridges', Bridge Management 4, Eds. M.J. Ryall, G.A.R. Parke \& J.E. Harding, Thomas Telford, London, pp. 442-449.

Jacob, B. and OBrien, E.J. 2005. 'Weigh-In-Motion: Recent Developments in Europe', 4th International Conference on Weigh-In-Motion - ICWIM4, Eds. E.J. OBrien, B. Jacob, A. Gonzalez \& C.-P. Chou, National Taiwan University, pp. 313.

Jacob, B. et al., 2010. US bridge formula (FBF-B) and implications of its possible application in Europe. In Frangopol, Sause, \& Kusko, eds. Bridge Maintenance, Safety, Management and Life-Cycle Optimization. Philadelphia: Taylor \& Francis Group, pp. 2875-2880.

Miao, T. J. and Chan, T. H. T. 2002. Bridge live load models from WIM data. Engineering Structures; 24: 1071-84.

Moses, F. 2001. Calibration of load factors for LRFR Bridge Evaluation: NCHRP Report No. 454. Washington D.C.: Transportation Research Board.

Nowak, A. S. 1993. Live load model for highway bridges. Structural Safety; 13: 53-66.

Nowak, A. S. 1994. Load model for bridge design code. Canadian Journal of Civil Engineering 1994; 21: 36-49.

OBrien, E. \& Enright, B., 2012. Using Weigh-In-Motion Data to Determine Aggressiveness of Traffic for Bridge Loading. Journal of Bridge Engineering, ASCE. doi:10.1061/(ASCE)BE.1943-5592.0000368

OBrien, E., Enright, B. \& Getachew, A., 2010. Importance of the tail in truck weight modelling for bridge assessment. Journal of Bridge Engineering, ASCE, 15(2), pp.210-213.

O'Connor, A., Jacob, B., O'Brien, E. J. and Prat, M. 2001. Report of current studies performed on normal load model of EC1 Part 2. Traffic loads on bridges. Revue Française de Génie Civil 2001; 5 (4): 411-33.

Sivakumar, B. and Ibrahim, F. I. S. 2007. Enhancement of bridge live loads using weigh-in-motion data. Bridge Structures; 3 (3-4): 193-204.

Sivakumar, B., Moses, F., Fu, G. and Ghosn, M., 2007. Legal truck loads and AASHTO Legal Loads for Posting. NCHRP Report 575. Washington D.C.: Transportation Research Board.

USDOT. 2000. Comprehensive Truck Size and Weight Study. U.S. Department of Transportation. FHWA-PL-00-029. Retrieved from http://www.fhwa.dot.gov/policy/otps/truck/finalreport.htm

Walker, D. \& Cebon, D., 2012. The Metamorphosis of LTPP Traffic Data. In 6th International Conference on Weigh-InMotion. Dallas, pp. 242 - 249. 